\title{
Jailed balloons for side branch protection: a review of techniques and literature
}

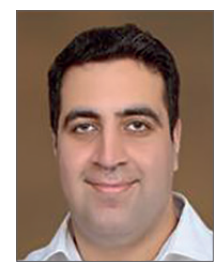

Bilal Kabeer Khan*, MBBS, FCPS; Muhammad Nasir Rahman, MBBS, FCPS, FCPS; Javed Majid Tai, MBBS, FCPS, FCPS; Osman Faheem, MD, FACC

Department of Medicine, Aga Khan University Hospital, Stadium Road, Karachi, Pakistan

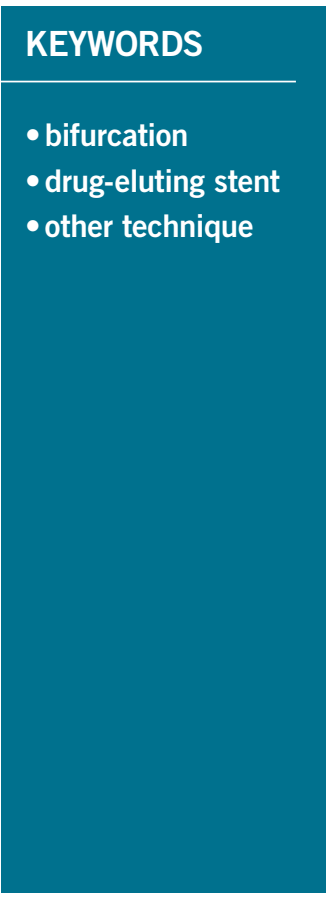

\section{Abstract}

Coronary bifurcation lesions are commonly encountered, and side branch compromise is a major complication of these bifurcation interventions. Jailing a wire in the side branch is the most common method of significant side branch protection. Jailing a balloon in the side branch is a less well known and seldom practiced strategy of side branch preservation but tends to have lower occlusion rates as compared to conventional jailed wires. Various modifications have been applied to the original jailed balloon technique to further improve side branch patency. Complications arising from this technique have been limited to case reports only and relate mainly to calcified vessels.

*Corresponding author: Department of Medicine, Aga Khan University Hospital, National Stadium Rd, Karachi, Karachi City, Sindh 74800, Pakistan.E-mail: bilal.kabeer.khan@gmail.com 


$\begin{array}{ll}\text { Abbreviations } \\ \text { BSKT } & \text { balloon stent kissing technique } \\ \text { IVUS } & \text { intravascular ultrasound } \\ \text { JBT } & \text { jailed balloon technique } \\ \text { JWT } & \text { jailed wire technique } \\ \text { LAD } & \text { left anterior descending artery } \\ \text { Diag } & \text { diagonal artery } \\ \text { LCX } & \text { left circumflex artery } \\ \text { OM } & \text { obtuse marginal artery } \\ \text { MB } & \text { main branch } \\ \text { MV } & \text { main vessel } \\ \text { ODFI } & \text { optical domain frequency imaging } \\ \text { POT } & \text { proximal optimisation technique } \\ \text { RI } & \text { ramus intermedius } \\ \text { SB } & \text { side branch } \\ \text { TAP } & \text { T-stenting and protrusion } \\ \text { TLR } & \text { target lesion revascularisation }\end{array}$

\section{Introduction}

Coronary bifurcation lesions represent a challenge to the interventional cardiologist and account for up to $20 \%$ of all lesions encountered in clinical practice, and side branch (SB) compromise is a major complication of stenting these bifurcation lesions ${ }^{1}$. The subject of a lot of investigations, provisional stenting has been proven to be superior to a two-stent strategy in most long term outcomes $^{2,3}$. Until now, a two-stent strategy has been shown to be superior in complex left main lesions only ${ }^{4}$. The most commonly employed strategy to protect a significant SB during provisional stenting is to jail a coronary wire in the SB, which maintains SB patency, modifies SB angle and acts as a marker for rewiring ${ }^{5,6}$. In the multicentre TULIPE study, absence of a jailed wire resulted in higher rates of target lesion revascularisation (TLR) but despite these measures the CACTUS study still reported an inability to salvage the $\mathrm{SB}$ in $1.1 \%$ of cases $^{7,8}$. In an attempt to develop a superior SB protection strategy, Burzotta et al, in 2010, published their bench test report and first clinical experience on "Jailed balloon protection..." 9 . They proposed it as a novel technique to preserve SB patency during provisional main vessel (MV) stenting in cases where there is a high risk of side branch compromise ${ }^{9}$. For this article we have reviewed 107 papers that were identified through a PubMed search.

\section{Classification of bifurcation lesions and bifurcation stenting techniques}

Numerous classifications of bifurcation lesions have been proposed; however, the European Bifurcation Club consensus document promotes a simplified classification, the Medina classification. In the Medina classification, any lesion with greater than $50 \%$ stenosis is considered significant. Significant lesions are denoted by " 1 " and insignificant lesions by " 0 ". Lesions are recorded in the following order: proximal main vessel, distal main vessel and side branch. These figures are separated by commas. The consensus document also endorses the MADS classification for bifurcation stenting techniques, which takes into account the position of stents in the bifurcation, and the order in which stenting is performed. In this classification, four distinct strategies have been described. Each strategy is represented by an acronym; "M" for main vessel first, "A" for main vessel across side branch first, "D" for distal vessel first and "S" for side branch first ${ }^{10-12}$.

\section{The "conventional" jailed balloon technique (JBT)}

In the original JBT (Figure 1A-Figure 1G) a stent was positioned in the main branch (MB) and a long semi-compliant balloon, with a proximal marker extending beyond the proximal marker of stent, was positioned in the SB. The MB stent was deployed and the SB assessed angiographically. If the SB was not occluded then the SB balloon was withdrawn, followed by proximal optimisation of the stent with a short balloon. The SB was subsequently rewired, and kissing balloon inflation performed. If the SB was occluded, then the jailed balloon was inflated resulting in stent distortion and restoration of flow. The remaining steps were the same, including proximal optimisation (POT), side branch rewiring and final kissing balloon inflation. A greater occupancy of the SB ostium is proposed to ensure better side branch patency. Resistance during balloon withdrawal was deemed equivalent to that encountered during jailed wire removal and in case of more than usual resistance, a low-pressure inflation was recommended rather than application of force. No major MB stent malapposition was observed 9 .

One drawback of the procedure is that it becomes quite complex when a SB becomes occluded (Figure 2A-Figure 2H), although SB occlusion was reported in only 1 out of 19 cases $^{9}$. In such cases the SB balloon should be deployed, but for it to be deployed, another balloon has to be positioned in the MB to immediately correct any stent distortion that results after SB balloon deployment. Any residual distortion would make rewiring challenging. To correct distortion, vascular injury and edge dissections are possible. In case stenting of the side branch is required, an inverted "provisional crush" technique is recommended, but it would be difficult to track a stent through a MB stent with any degree of residual distortion.

\section{"Simplified" jailed balloon technique}

Singh et al published an independently developed simplified JBT in $2012^{13}$. In this technique (Figure 3) both MB and SB were wired followed by predilatation of the MB with a semi-compliant balloon. Stent placement in the MB and long semi-compliant balloon placement in the SB were followed by stent deployment. If the SB was patent, then the SB balloon was inflated at low pressure (less than 3 atmospheres), deflated and subsequently removed along with the SB wire. However, if the SB was compromised; a routine balloon angioplasty was performed restoring SB flow but causing malapposition of the $\mathrm{MB}$ stent. In this technique, rather than using a short balloon to optimise the stent, the stent balloon itself was used to optimise stent apposition by inflation 


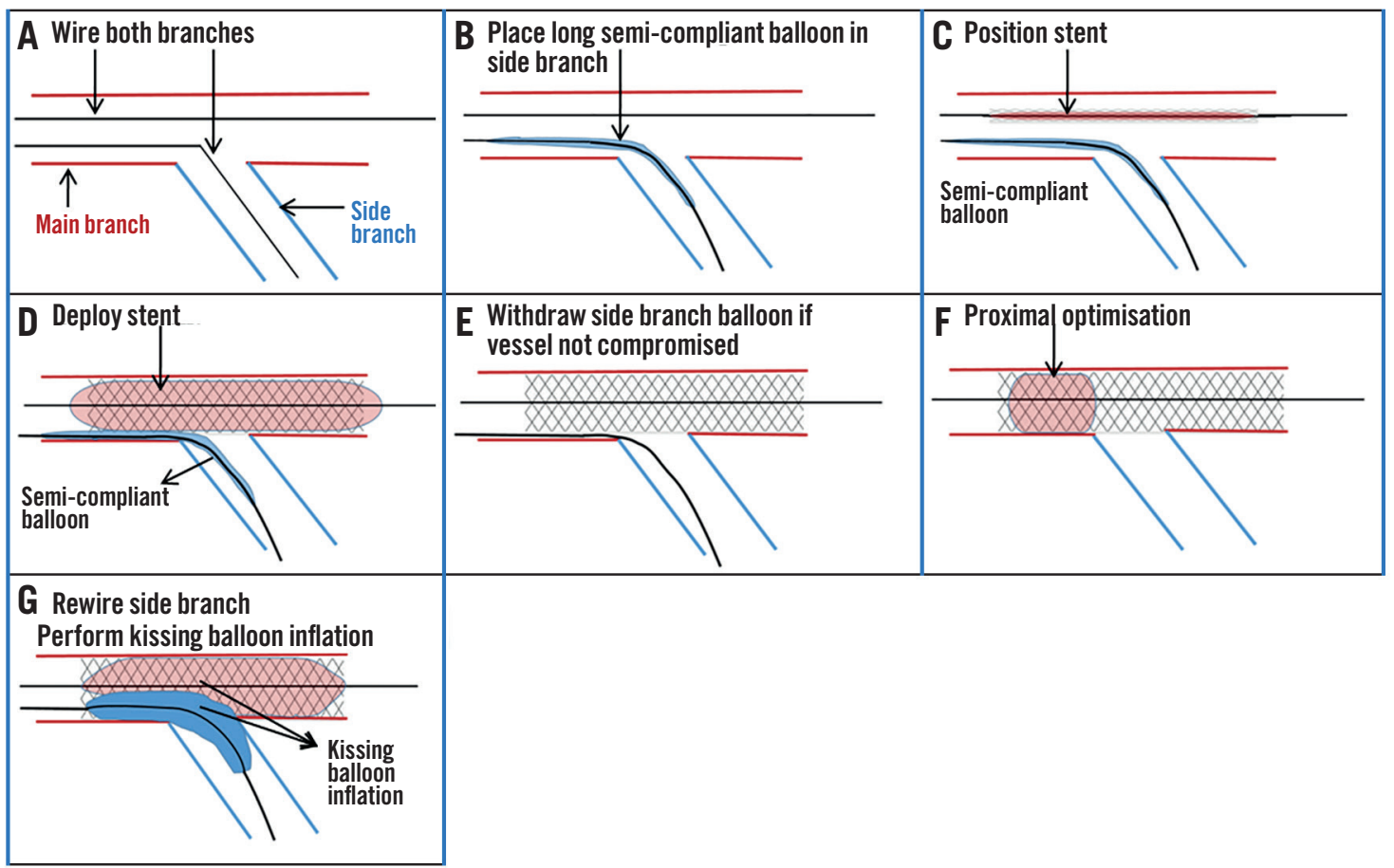

Figure 1. Stepwise "conventional" jailed balloon technique without side branch is not compromised.

to supra-nominal pressures. No kissing balloon inflation was performed. Out of a total of 102 patients who underwent percutaneous coronary intervention using this technique, only nine side branches had to be re-crossed with wires and only two required stenting ${ }^{13}$.
This technique appears simpler than the conventional approach, but at the same time, the use of a compliant stent balloon for proximal optimisation needs to be questioned. The variable expansion profile of compliant balloons can result in edge dissection and stent under-expansion. Also, routine low pressure balloon inflation

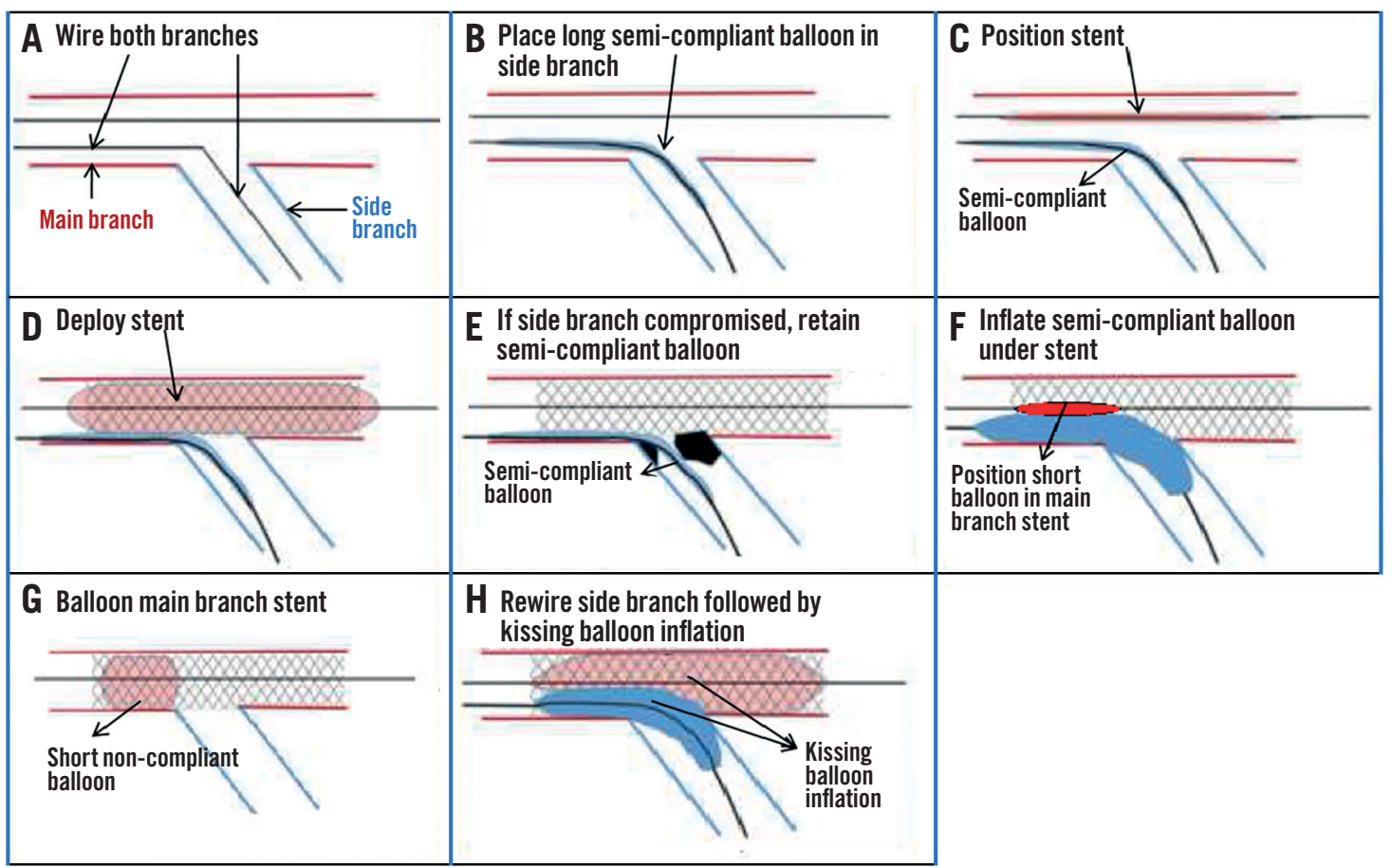

Figure 2. Stepwise "conventional" jailed balloon technique with side branch compromise. 


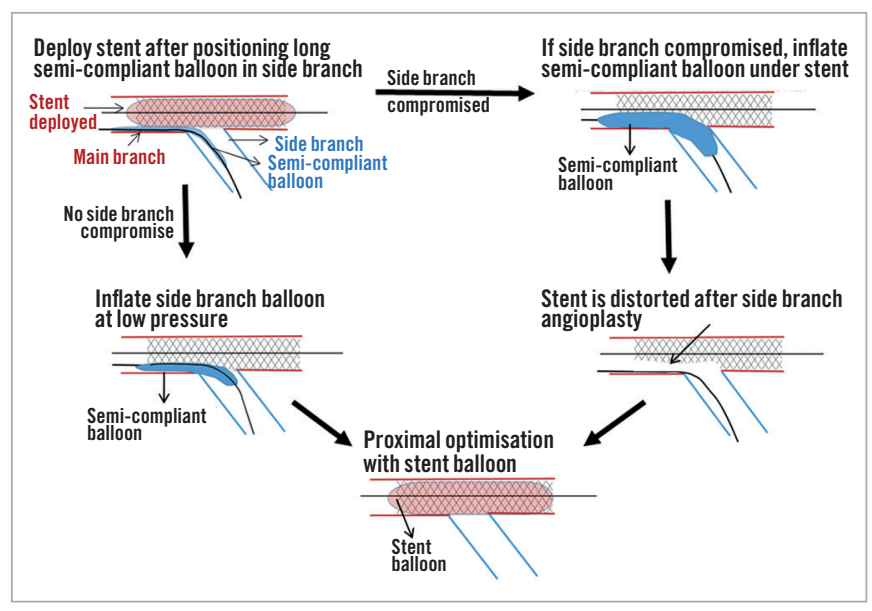

Figure 3. "Simplified" jailed balloon technique with and without side branch compromise. Final proximal optimisation is performed with stent balloon.

in the absence of any SB compromise may be unnecessary. IVUS was performed in $74 \%$ patients (at operator's discretion) and on the basis of this, $41 \%$ of lesions required further intervention. This is quite intriguing and underscores the importance of incorporating intravascular imaging while performing jailed balloon techniques. It also raises questions about whether a suboptimal intervention may be performed when JBT are used without intravascular imaging. It should also be mentioned that left main bifurcation lesions were excluded.

\section{Jailed semi-inflated balloon technique}

Although results of the simplified JBT were promising, it did not completely prevent SB occlusion ${ }^{7}$. A further modification of this technique known as the jailed semi-inflated balloon technique has been proposed to further improve SB patency (Figure 4A-Figure 4C). This technique follows the same basic principles as the simplified JBT with respect to balloon length and positioning; however, the SB balloon (sized 1:1 as per SB diameter) is simultaneously inflated at low pressures (3 atm) while the MB stent is deployed. As the MB stent is deployed, the proximal segment of the SB balloon is compressed and the distal part is over-inflated to completely occupy the SB ostium and prevent plaque shift. Final POT is performed with a short non-compliant balloon ${ }^{14}$.

Despite a theoretical risk of balloon entrapment due to loss of profile, no cases of entrapment were encountered. Another point of concern is trauma to SB ostia from the semi-inflated balloon. This concern was shared by the authors of the jailed semi-inflated balloon technique and they proposed that the SB balloon could be

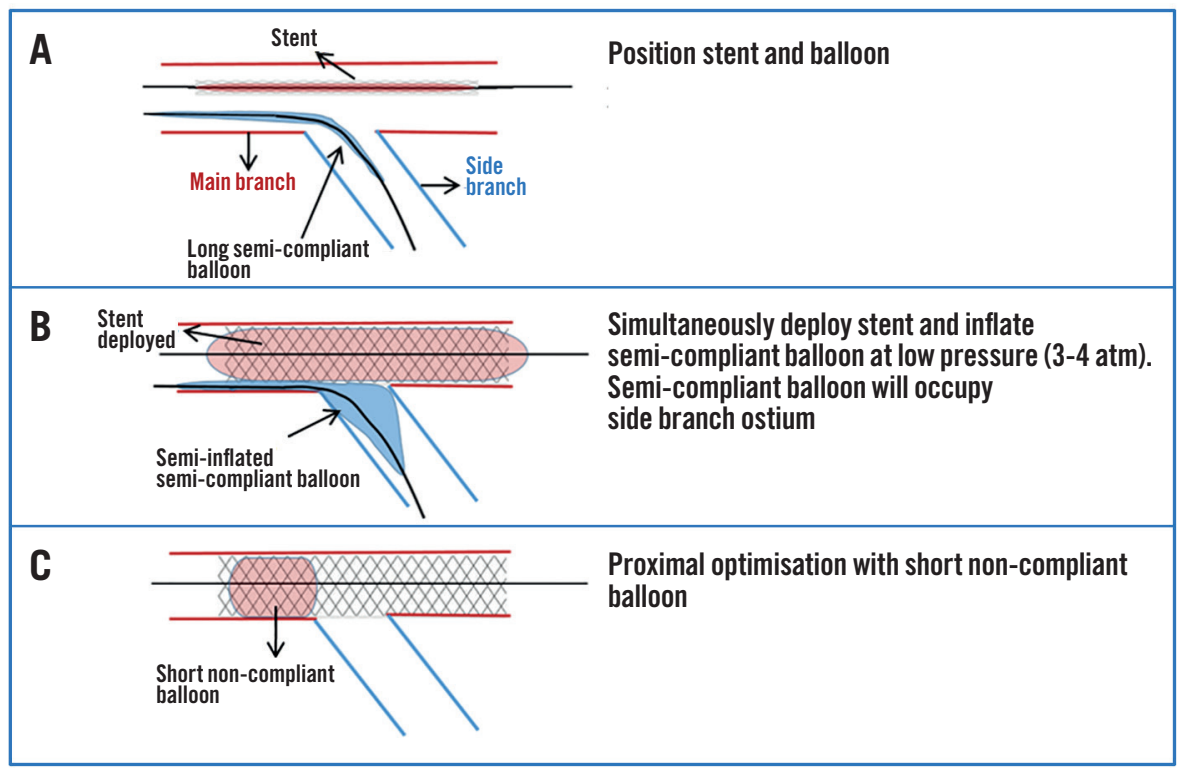

Figure 4. Jailed semi-inflated balloon technique. The side branch balloon is inflated at low pressure during stent deployment. Final proximal optimisation is performed with a short balloon. 
slightly undersized. IVUS was performed in $25 \%$ patients enrolled in the study. Out of 142 patients, stent underexpansion occurred in $16.2 \%$ of cases and IVUS revealed $5.4 \%$ with proximal edge dissection. The better results of the jailed semi-inflated balloon technique on IVUS as compared to the simplified JBT could be due to the use of non-compliant balloons for POT.

Ermiş et al published their experience with this technique ${ }^{15}$. Out of 82 bifurcation lesions in 64 patients $(60.9 \%$ of whom had presented with acute coronary syndrome), only 5 cases of SB occlusion were reported that required intervention. Interestingly, the SB balloon was inflated to higher pressures than usual $(4.8 \pm 2.0 \mathrm{~atm})^{15}$.

\section{"Modified" jailed balloon technique and balloon stent kissing technique}

Modified JBT is a technique that has been studied only recently; the proximal marker of the $\mathrm{SB}$ balloon is positioned so that it touches the MB stent (Figure 5A-Figure 5C). In all other JBT the proximal marker is placed proximal to $\mathrm{MB}$ stent. The SB balloon diameter was selected as half of the MB stent diameter, if this did not exceed the diameter of the SB. Both balloons were then deployed simultaneously, withdrawn and wires crossed. Final kissing balloon inflation was performed at the operator's discretion and if the SB required stenting, a T-stenting and protrusion (TAP) technique was employed (Figure 5). S. Saito and colleagues carried out in vitro testing with optical frequency domain imaging (OFDI) used to determine the "eccentricity index" (ratio between maximum and minimum stent diameters in main branch), which was found to be greater with conventional JBT as compared to modified JBT in proximal segment of bifurcation. No difference in eccentricity index was observed in the distal segment of bifurcation. Out of 254 bifurcation lesions that were treated by the modified JTB method, $253(99.6 \%)$ side branches showed post intervention TIMI III flow ${ }^{16}$.

A recently published study of patients managed by this technique reported no adverse outcomes at 9-month follow-up. However, this study did not compare outcomes with any other technique and had a small sample size ${ }^{17}$.

The "balloon stent kissing technique" varies slightly from the modified jailed balloon technique as the balloon is placed slightly more proximally but not proximal to stent. Cohort analysis of this technique showed superior immediate results as compared to provisional stenting in terms of side branch patency and TIMI flow, but no difference in outcomes was observed at 12-month follow-up. Only true bifurcation lesions were included and complex bifurcations were excluded. Despite a theoretical risk, no cases of balloon entrapment or damage were reported with either technique ${ }^{16,18}$.

\section{Jailed stent balloon technique}

The jailed stent balloon technique is a dedicated two-stent strategy recently published by Shpigel et $\mathrm{al}^{19}$. It involves balloon angioplasty of both MB and SB lesions followed by stenting of the SB first. The SB stent balloon is partially withdrawn and MB stent is

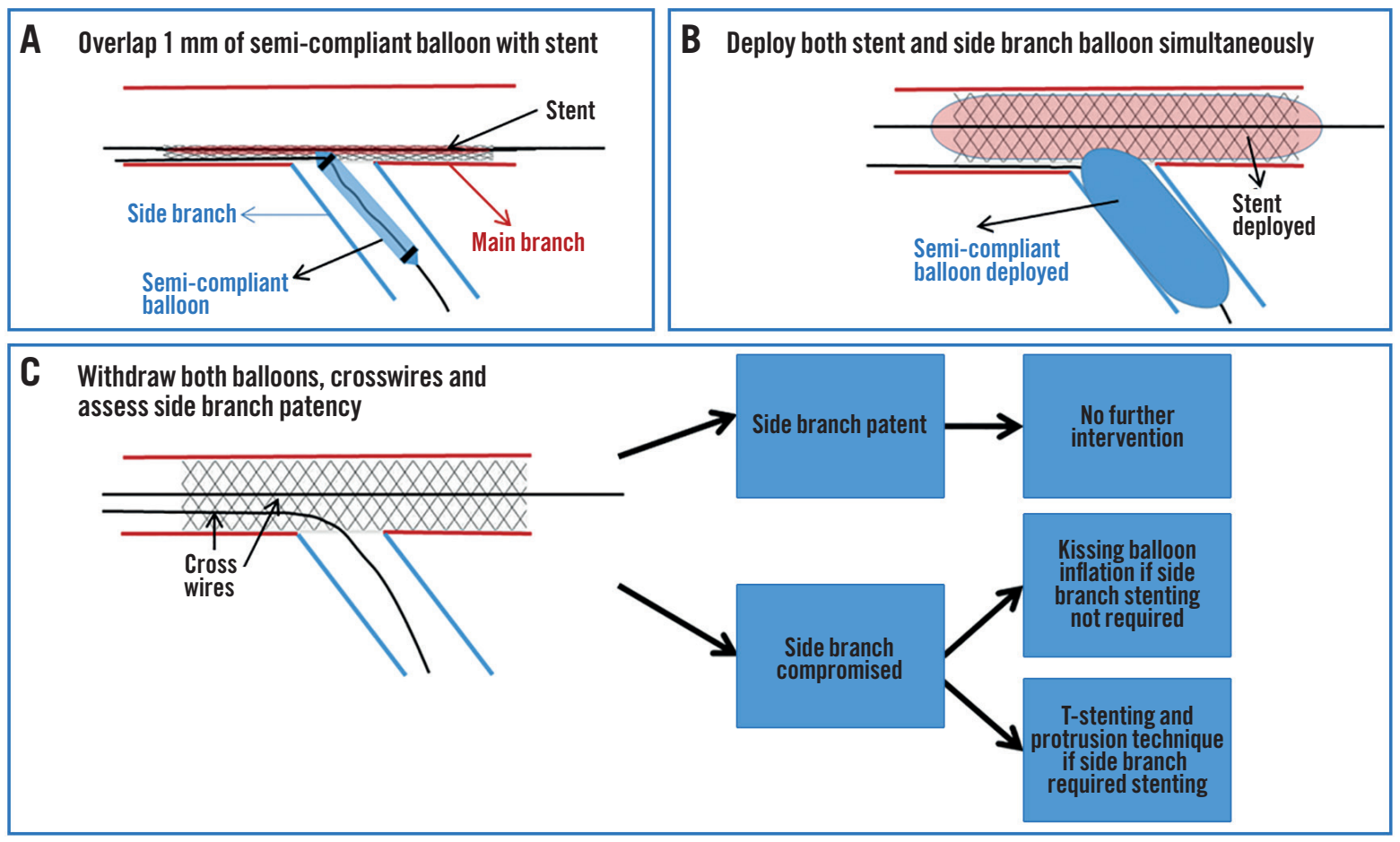

Figure 5. Modified jailed balloon technique. Side branch balloon is positioned so that it protrudes about 1 mm into main branch. If the side branch is compromised, a kissing balloon inflation or T-stenting and protrusion is performed. 
deployed. This is followed by sequential redeployment of SB and then MB stent balloons to correct any deformities. Final rewiring with kissing balloon dilatation or proximal optimisation (POT) is optional (Figure 6A-Figure 6F). Procedural success was observed in $100 \%$ of the 34 patients treated. At 2-year follow up only one patient required TLR, and TLR/ binary stenosis occurred in three patients ${ }^{19}$.

This method quotes a high success rate but it is unclear whether there is a need to jail a balloon in the SB if a stent has already been properly deployed to cover the ostium of the SB. Jailing a stent balloon between two layers of stents also poses significant risk of entrapment.

\section{Jailed balloon and Corsair trifurcation technique}

Limited to case reports, this technique integrates the jailed semiinflated balloon technique with the "jailed Corsair technique" that was published in a 2017 case report by Numusawa and colleagues $^{20}$. Munakata et al reported a left main trifurcation lesion (modified Medina classification 1,1,1,0) managed with this technique. They employed a cross-stenting strategy from the left main coronary artery (LMCA) into the left anterior descending artery (LAD) while at the same time positioning a semi-inflated (3 atm) balloon in the ramus intermedius (RI) and a Corsair micro-catheter (Asahi Intecc, Aichi, Japan) in the left circumflex (LCx) artery. The stent was deployed jailing both balloon and microcatheter, which were withdrawn post stent deployment. This was followed by rewiring of both the RI and LCx. Kissing balloon dilatation was performed in both the LAD and RI followed by the $\mathrm{LAD}$ and $\mathrm{LCX}^{21}$.
In our opinion, all of the jailed balloon techniques can be incorporated into a trifurcation strategy. Jailing a second device, in this case a micro-catheter, increases the complexity of the procedure, chances of device entrapment and stent deformity. Another possibility that should be considered is that inter-twining of the coronary wire of the jailed balloon and the micro-catheter around each other could cause difficulty in device withdrawal.

\section{Complications}

The most dreaded complication of this technique is entrapment of the jailed balloon. This has been reported in case reports in calcified lesions despite plaque modification with rotational atherectomy. The jailed balloon is eventually withdrawn in these cases with manual traction causing deformation of the stent, in one case requiring correction with proximal optimisation. Another significant area of concern identified by one of the case reports was that repeated balloon inflation and deflation to rescue the trapped balloon itself will cause loss of balloon profile, and this loss of balloon profile may further hinder balloon withdrawal ${ }^{22,23}$. Although these complications are limited to case reports only, and were successfully managed on each occasion, inability to retrieve a balloon would be catastrophic and surely lead to emergent surgery. Moreover, in comparison, a trapped wire would be easier to release and retrieve than a trapped balloon.

\section{Discussion}

The effectiveness of the JBT was demonstrated in a recent publication by Omori et al where a pressure wire assessment of JBT efficacy was performed. The $\mathrm{Pd} / \mathrm{Pa}$ in the SB immediately after

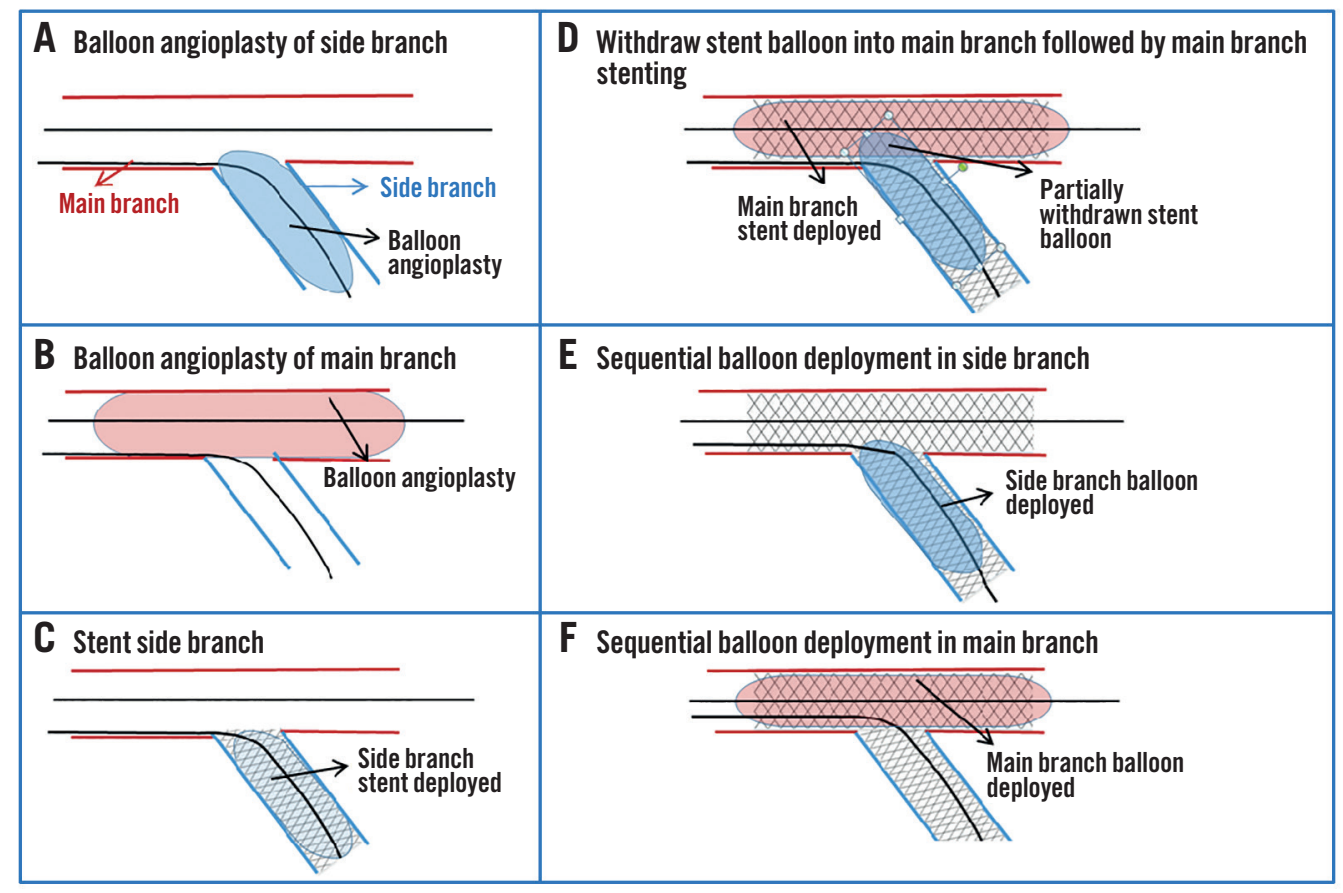

Figure 6. Stepwise jailed stent balloon technique. 
stenting was 0.34 , which increased to 0.60 after balloon removal. Although still suboptimal, it showed that a jailed balloon can secure lumen patency in the jailed $\mathrm{SB}^{24}$.

We have summarised literature from some of the major trials on jailed balloon techniques in Table 1-Table 3. In terms of patient characteristics, most patients enrolled were hypertensive, nondiabetic males in their $60 \mathrm{~s}$ and $70 \mathrm{~s}$ without prior coronary intervention except in the modified JBT trial where half of the patients had undergone prior coronary intervention. The modified JBT and balloon stent kissing technique (BSKT) group of patients also differed from the others in that the majority of these patients were diagnosed with stable angina whereas the other trials had enrolled predominantly acute coronary syndrome patients (Table 1). The majority of lesions treated were LAD/diagonal bifurcations. LM lesions had been excluded in the simplified JBT and BSKT trials. Most of the lesions treated were classified as Medina 1,1,1. The procedure was performed predominantly with a 6 Fr guide catheter and through a transradial access. A variety of stent platforms were used and had similar outcomes (Table 2). IVUS, when performed, showed less well apposed stents with simplified JBT, which may be due to the use of compliant stent balloons for optimisation. The jailed semi-inflated balloon technique reported significantly more well apposed stents as it involved POT with a non-compliant balloon. In both these studies, only two edge dissections were reported. Although it would have been interesting to compare procedural times between the different techniques and to traditional wire trapping, only Cayli et $\mathrm{al}^{14}$ measured procedural times and they were reported as $16.3 \pm 4.8$ minutes. Procedural success rates were $100 \%$ and only one side branch was lost with the simplified JBT. No cases of balloon damage or entrapment were reported. The role of intravascular imaging with jailed balloon techniques needs to be stressed. Malapposition, that may or may not be related to balloon jailing, can be effectively identified and corrected along with any edge dissections. Table 3 summarises these outcomes and IVUS findings $\mathrm{s}^{9,13,14,16,18}$. It is important to highlight here that the main limitation of these techniques is the limited data. Direct comparison between various jailed balloon techniques is not possible, and in our review of literature, no studies in this regard have been performed to date. However, we found two studies that had compared the jailed wire technique (JWT) with JBT. The first is a randomised control trial from China where 192 consecutive patients were randomised to JBT or JWT and immediate post-procedural outcomes were studied. Only patients with Medina 1,1,1 lesions were enrolled. In this study SB TIMI III flow was achieved less frequently in patients who underwent JWT than those who underwent JBT (74.6\% vs 93.2\%, $\mathrm{p}=0.001)$. Patients undergoing JWT also experienced more periprocedural MI $(11.9 \%$ vs $2.7 \%, \mathrm{p}=0.008)$ and more SB occlusion ( $18.6 \%$ vs $5.4 \%, \mathrm{p}=0.009)$. No device-related complication was reported in the study ${ }^{25}$. Results from a prospective double-blinded randomised control trial involving patients with true bifurcation lesions (Medina classification 1.1.1, 1.0.1, or 0.1.1) showed a lower incidence of perioperative MACE with BSKT than with JWT ( $0 \%$ vs $13.6 \%, \mathrm{p} \leq 0.05)$. The incidence of MACE, angina and heart failure was similar on median follow-up of $19.0 \pm 6.1$ months. There was no difference in survival between the two groups at 24 months (BSKT 97.7\% vs JWT 91.1\%, $\mathrm{p}=0.18$ ). Although these results are promising, they may not be easily replicated. The data are limited to single centres where the procedure would have been performed by operators who specialised in the $\mathrm{JBT}^{26}$. To show superiority, adequately powered studies with a control arm, intravascular imaging and medium to long

Table 1. Literature review of jailed balloon techniques- a comparison of clinical characteristics.

\begin{tabular}{|c|c|c|c|c|c|}
\hline & Burzotta et $a^{l^{9}}$ & Singh et al ${ }^{13}$ & Çayli et al ${ }^{14}$ & Saito et al ${ }^{16}$ & Qu et $\left.a\right|^{18}$ \\
\hline Technique & Conventional JBT & $\begin{array}{l}\text { Simplified } \\
\text { JBT }\end{array}$ & $\begin{array}{l}\text { Jailed semi-inflated } \\
\text { balloon }\end{array}$ & $\begin{array}{l}\text { Modified jailed } \\
\text { balloon technique }\end{array}$ & $\begin{array}{l}\text { Balloon stent kissing } \\
\text { technique }\end{array}$ \\
\hline Total Patients & 19 & 100 & 137 & 233 & 40 \\
\hline Age $(n \pm S D / I Q R)$ & $69.0 \pm 7.3$ & $63.1 \pm 11.7$ & $63.6 \pm 11.7$ & $71.5 \pm 9.7$ & $62 \mathrm{IQR} 12$ \\
\hline Females & $7(35 \%)$ & 39 (39\%) & $33(24.1 \%)$ & $11(18.3)$ & $10(25 \%)$ \\
\hline Diabetes mellitus & $8(40 \%)$ & $33(33 \%)$ & $54(39.4 \%)$ & $98(42.1)$ & $14(35 \%)$ \\
\hline Hypertension & - & $88(88 \%)$ & $72(52.6 \%)$ & $181(77.7 \%)$ & $28(70 \%)$ \\
\hline Smoker & - & $45(45 \%)$ & $52(38.0 \%)$ & $120(51.5 \%)$ & $15(37.5 \%)$ \\
\hline Dyslipidaemia & - & $84(84 \%)$ & $64(46.7 \%)$ & $186(79.8 \%)$ & $14(35 \%)$ \\
\hline Prior CAD & - & $48(48 \%)$ & & & \\
\hline Prior coronary bypass graft & - & $13(13 \%)$ & $19(13.9 \%)$ & $5(2.1 \%)$ & $1(2.5 \%)$ \\
\hline Prior $\mathrm{PCl}$ & - & $13(13 \%)$ & $41(29.9 \%)$ & $114(48.9 \%)$ & $6(15 \%)$ \\
\hline Peripheral arterial disease & - & $3(7 \%)$ & - & - & - \\
\hline Chronic kidney disease & - & $7(7 \%)$ & - & $112(48.1 \%)$ & $1(2.5 \%)$ \\
\hline Stable angina & $13(65 \%)$ & $17(17 \%)$ & 49 (35.8\%) & $197(84.5 \%)$ & $28(70 \%)$ \\
\hline Acute coronary syndrome & $7(35 \%)$ & $68(68 \%)$ & $88(64.2 \%)$ & $36(15.5 \%)$ & $12(30 \%)$ \\
\hline
\end{tabular}


Table 2. Literature review of jailed balloon techniques- angiographic and lesion characterisitics

\begin{tabular}{|c|c|c|c|c|c|}
\hline & Burzotta et $\mathrm{al}^{9}$ & Singh et al ${ }^{13}$ & Çayli et al ${ }^{14}$ & Saito et al ${ }^{16}$ & Qu et $\left.a\right|^{18}$ \\
\hline Technique & Conventional JBT & $\begin{array}{c}\text { Simplified } \\
\text { JBT }\end{array}$ & $\begin{array}{l}\text { Jailed semi-inflated } \\
\text { balloon }\end{array}$ & Modified JBT & BSKT \\
\hline Left Main (n, \%) & $11(55 \%)$ & 0 & 28 (18.9\%) & $54(21.3 \%)$ & 0 \\
\hline LAD/ Diagonal $(n, \%)$ & 7 (35\%) & $50(49 \%)$ & 85 (57.4\%) & $148(58.3 \%)$ & 27 (67.5\%) \\
\hline LCX/ OM (n, \%) & $2(10 \%)$ & $16(16 \%)$ & $26(17.6 \%)$ & $32(12.6 \%)$ & $2(5.0 \%)$ \\
\hline Medina $1,1,1(\mathrm{n}, \%)$ & $17(85 \%)$ & $93(91 \%)$ & $93(62.8 \%)$ & $53(20.9 \%)$ & $31(77.5 \%)$ \\
\hline Medina $0,1,1(n, \%)$ & $1(10 \%)$ & $2(2 \%)$ & $3(2.0 \%)$ & $68(26.8 \%)$ & $5(12.5 \%)$ \\
\hline Medina $1,0,1(n, \%)$ & $2(10 \%)$ & $1(1 \%)$ & $13(8.8 \%)$ & $33(13.0 \%)$ & $4(10.0 \%)$ \\
\hline $\begin{array}{l}\text { Bifurcation angle } \\
\text { (degree, n, \%) }\end{array}$ & - & - & $\begin{array}{r}<70,102(68.9) \\
70-90,25(16.9) \\
>90,21(14.2)\end{array}$ & $\begin{array}{r}<30,43(16.9) \\
30-60,97(38.2) \\
>60,114(44.9)\end{array}$ & - \\
\hline Radial cases (n, \%) & $12(60 \%)$ & - & $23(16.8 \%)$ & $213(91.4 \%)$ & - \\
\hline 6 Fr system (n, \%) & $20(100 \%)$ & - & - & $227(89.4 \%)$ & - \\
\hline Predilation MV (n, \%) & $17(85 \%)$ & - & 81 (54.7\%) & $246(96.9 \%)$ & - \\
\hline Predilation SB (n, \%) & $3(15 \%)$ & - & $22(14.9 \%)$ & $20(7.9 \%)$ & - \\
\hline \multicolumn{6}{|l|}{ MV stent } \\
\hline BMS (n, \%) & 0 & 17 (17\%) & 0 & 0 & 0 \\
\hline \multicolumn{6}{|l|}{ Drug-eluting stent } \\
\hline sirolimus (n, \%) & $1(5 \%)$ & $17(17 \%)$ & 0 & - & - \\
\hline everolimus (n, \%) & 7 (35\%) & $53(52 \%)$ & $32(21.6 \%)$ & 125 (49.2\%) & \\
\hline paclitaxel $(n, \%)$ & $3(15 \%)$ & $5(5 \%)$ & 0 & - & - \\
\hline zotarolimus (n, \%) & $6(30 \%)$ & $11(11 \%)$ & $35(23.7 \%)$ & $37(14.6 \%)$ & - \\
\hline biolimus (n, \%) & $3(15 \%)$ & 0 & $81(54.7 \%)$ & $3(1.2 \%)$ & - \\
\hline Ultimaster (n, \%) & 0 & 0 & 0 & $64(25.2 \%)$ & - \\
\hline SYNERGY $(n, \%)$ & 0 & 0 & 0 & $25(9.8 \%)$ & - \\
\hline MV stent diameter $(\mathrm{mm} \pm \mathrm{SD})$ & $3.5 \pm 0.5$ & - & $2.9 \pm 0.3$ & $3.2 \pm 0.4$ & - \\
\hline MV stent length $(\mathrm{mm} \pm \mathrm{SD})$ & $22.6 \pm 5.2$ & - & $24.0 . \pm 6.8$ & $24.4 \pm 6.7$ & - \\
\hline POT (n, \%) & $10(50 \%)$ & 0 & $137(100 \%)$ & 40 (100\%) & \\
\hline $\mathrm{KBI}(\mathrm{n}, \%)$ & $20(100 \%)$ & $\begin{array}{c}7(7 \%) \\
\text { as rescue }\end{array}$ & $\begin{array}{l}3(2.0 \%) \text { - final } \\
\text { kissing balloon }\end{array}$ & $183(72.1 \%)$ & $\begin{array}{l}7(17.5 \%) \\
\text { as rescue }\end{array}$ \\
\hline SB stenting (n, \%) & $10(53 \%)$ & $2(2 \%)$ & $3(2.0 \%)$ & $31(12.2 \%)$ & $0(0 \%)$ \\
\hline $\mathrm{SB}$ stent diameter $(\mathrm{mm} \pm \mathrm{SD})$ & $3.2 \pm 0.4$ & - & - & $2.6 \pm 0.3$ & - \\
\hline SB stent length $(m m \pm S D)$ & $16.6 \pm 5.4$ & - & - & $15.4 \pm 7.0$ & - \\
\hline
\end{tabular}

term follow-up would be required. Thus, although the authors do not recommend the routine use of the JBT, in the absence of any robust data proving superiority over the JWT, there may be a potential role for the JBT in selected patients.

\section{Conclusion}

The jailed balloon technique appears safe and effective for SB preservation. However, most operators have limited-to-no experience of the technique. Current data are limited, single-centered and, in the absence of head to head trials, the JTB offers no definitive advantage over the JWT. Multicentred randomised studies are required to directly compare the various jailed balloon techniques with each other and with the JWT.

\section{Conflict of interest statement}

The authors have no conflicts of interest to declare.

\section{References}

1. Collins N, Seidelin PH, Daly P, Ivanov J, Barolet A, Mackie K, Bui S, Schwartz L, Džavík V. Long-term outcomes after percutaneous coronary intervention of bifurcation narrowings. Am J Cardiol. 2008;102:404-10.

2. Steigen T, Holm N, Kumsars I, Niemela M, James S, Erglis A, Kervinen K, Jensen JS, Galloe AM, Wiseth R, Gunnes P, Meyerdierks O, Rotevatn S, Vikman S, Maeng M, Ravkilde J, Ylitalo A, Helqvist S, Sjogren I, Okkels Jensen L, Laine M, Hartikainen J, Airaksinen J, Flensted Lassen J, Thuesen L, 
Table 3. Literature review of jailed balloon techniques- intracoronary imaging and outcomes.

\begin{tabular}{|c|c|c|c|c|c|}
\hline & Burzotta et $a^{9}$ & Singh et al ${ }^{13}$ & Çayli et al ${ }^{14}$ & Saito et al ${ }^{16}$ & Qu et $\mathrm{al}^{18}$ \\
\hline Technique & Conventional JBT & $\begin{array}{l}\text { Simplified } \\
\text { JBT }\end{array}$ & $\begin{array}{l}\text { Jailed semi-inflated } \\
\text { balloon }\end{array}$ & $\begin{array}{c}\text { Modified jailed } \\
\text { balloon technique }\end{array}$ & $\begin{array}{l}\text { Balloon stent kissing } \\
\text { technique }\end{array}$ \\
\hline Intracoronary imaging (n, \%) & No & IVUS 75 (74\%) & IVUS 37 (25\%) & $\begin{array}{c}\text { IVUS } 234(92.1) \\
\text { OCT } 12(4.7) \\
\text { OFDI } 2(0.8)\end{array}$ & No \\
\hline $\begin{array}{l}\text { Well-apposed stent without } \\
\text { complication(n, \%) }\end{array}$ & - & $44(59 \%)$ & 29 (78.4\%) & - & - \\
\hline Stent under-expansion ( $\mathrm{n}, \%)$ & - & $23(31 \%)$ & $6(16.2 \%)$ & - & - \\
\hline Edge dissection (n, \%) & - & $2(3 \%)$ & 2 (5.4\%) Proximal & - & - \\
\hline Stent fracture $(n, \%)$ & - & $0(0 \%)$ & $0(0 \%)$ & - & - \\
\hline Stent strut distortion ( $\mathrm{n}, \%$ ) & - & $1(1 \%)$ & $0(0 \%)$ & - & - \\
\hline $\begin{array}{l}\text { IVUS finding prompting further } \\
\text { intervention }(\mathrm{n}, \%)\end{array}$ & - & $31(41 \%)$ & - & - & - \\
\hline Plaque shift (n, \%) & - & $4(5 \%)$ & - & - & - \\
\hline Malapposition (n, \%) & - & $1(1 \%)$ & - & - & - \\
\hline Procedure time (minutes) & - & - & $16.3 \pm 4.8$ & - & - \\
\hline \multicolumn{6}{|l|}{ Outcomes } \\
\hline Procedural success (n, \%) & $20(100 \%)$ & $102(100 \%)$ & $148(100 \%)$ & $254(100 \%)$ & $40(100 \%)$ \\
\hline $\begin{array}{l}\text { TIMI } 3 \text { flow after procedure } \\
(n, \%)\end{array}$ & - & $\begin{array}{l}\text { MV } 102(100 \%) \\
\text { SB } 101(99 \%) \\
\end{array}$ & $\begin{array}{l}\text { MV148 (100\%) } \\
\text { SB } 148(100 \%)\end{array}$ & MV 253 (99.6) & $\begin{array}{l}\text { MV } 40(100 \%) \\
\text { SB } 37(92.5 \%)\end{array}$ \\
\hline Periprocedural MI (n, \%) & - & $1(1 \%)$ & 0 & 0 & - \\
\hline Dissection - edge (n, \%) & - & $4(4 \%)$ & $7(4.8 \%)$ & - & - \\
\hline Dissection - side branch (n, \%) & - & - & $4(2.7)$ & - & - \\
\hline Side branch loss (n, \%) & 0 & $1(1 \%)$ & 0 & 0 & - \\
\hline $\begin{array}{l}\text { Jailed balloon or wire } \\
\text { entrapment }(n, \%)\end{array}$ & 0 & 0 & 0 & 0 & 0 \\
\hline Jailed balloon rupture (n, \%) & 0 & 0 & 0 & 0 & 0 \\
\hline
\end{tabular}

Christiansen E. TCT-318 Ten-year All-cause Mortality after Simple versus Complex Stenting of Coronary Artery Bifurcation Lesions in the Randomized Nordic Bifurcation Study. J Am Coll Cardiol. 2016;68:B131-2.

3. Généreux P, Kumsars I, Lesiak M, Kini A, Fontos G, Slagboom T, Ungi I, Metzger DC, Wykrzykowska JJ, Stella PR, Bartorelli AL, Fearon WF, Lefèvre T, Feldman RL, LaSalle L, Francese DP, Onuma Y, Grundeken MJ, Garcia-Garcia HM, Laak LL, Cutlip DE, Kaplan AV, Serruys PW, Leon MB. A randomized trial of a dedicated bifurcation stent versus provisional stenting in the treatment of coronary bifurcation lesions. J Am Coll Cardiol. 2015;65: 533-43.

4. Chen SL, Zhang JJ, Han Y, Kan J, Chen L, Qiu C, Jiang T, Tao L, Zeng H, Li L, Xia Y, Gao C, Santoso T, Paiboon C, Wang Y, Kwan TW, Ye F, Tian N, Liu Z, Lin S, Lu C, Wen S, Hong L, Zhang Q, Sheiban I, Xu Y, Wang L, Rab TS, Li Z, Cheng G, Cui L, Leon MB, Stone GW. Double Kissing Crush Versus Provisional Stenting for Left Main Distal Bifurcation Lesions: DKCRUSH-V Randomized Trial. J Am Coll Cardiol. 2017;70:2605-17.

5. Louvard Y, Lefèvre T, Cherukupalli R, Tavolaro O, Loubeyre C, Dumas P, Morice MC. Favorable effect of the" jailed wire" technique when stenting bifurcation lesions. September 2003 The American Journal of Cardiology Conference: 15th Annual Transcatheter Cardiovascular Therapeutics Symposium Volume: 92. 62L-63L.

6. Zhang D, Xu B, Yin D, Li YP, He Y, You SJ, Qiao SB, Wu YJ, Yan HB, Yang YJ, Gao RL, Dou KF. Clinical and angiographic predictors of major side branch occlusion after main vessel stenting in coronary bifurcation lesions. Chin Med J (Engl). 2015;128:1471-8. 7. Brunel P, Lefevre T, Darremont O, Louvard Y. Provisional T-stenting and kissing balloon in the treatment of coronary bifurcation lesions: results of the French multicenter "TULIPE" study. Catheter Cardiovasc Interv. 2006;68:67-73.

8. Colombo A, Latib A, Airoldi F, Bramucci E, Saccà S, Violini R, Lettieri C, Zanini R, Sheiban I, Paloscia L, Grube E, Shofer J, Bolognese L, Orlndi M, Niccoli G. Response to Letter Regarding Article, "Randomized Study of the Crush Technique Versus Provisional Side-Branch Stenting in True Coronary Bifurcations: The CACTUS (Coronary Bifurcations: Application of the Crushing Technique Using Sirolimus-Eluting Stents) Study". Circulation. 2009;120:e64.

9. Burzotta F, Trani C, Sianos G. Jailed balloon protection: a new technique to avoid acute side-branch occlusion during provisional 
stenting of bifurcated lesions. Bench test report and first clinical experience. EuroIntervention. 2010;5:809-13.

10. Lassen JF, Holm NR, Banning A, Burzotta F, Lefèvre T, Chieffo A, Hildick-Smith D, Louvard Y, Stankovic G. Percutaneous coronary intervention for coronary bifurcation disease: 11th consensus document from the European Bifurcation Club. EuroIntervention. 2016;12:38-46.

11. Medina A, Suárez DL, Pan M. [A new classification of coronary bifurcation lesions]. Rev Esp Cardiol. 2006;59:183. [Article in Spanish]

12. Louvard Y, Thomas M, Dzavik V, Hildick-Smith D, Galassi AR, Pan M, Burzotta F, Zelizko M, Dudek D, Ludman P, Sheiban I. Classification of coronary artery bifurcation lesions and treatments: time for a consensus! Catheter Cardiovasc Interv. 2008;71: 175-83.

13. Singh J, Patel Y, Depta JP, Mathews SJ, Cyrus T, Zajarias A, Kurz HI, Lasala JM, Bach RG. A modified provisional stenting approach to coronary bifurcation lesions: clinical application of the “jailed-balloon technique”. J Interv Cardiol. 2012;25:289-96.

14. Çaylı M, Şeker T, Gür M, Elbasan Z, Şahin DY, Elbey MA, Çil H. A Novel-Modified Provisional Bifurcation Stenting Technique: Jailed Semi-Inflated Balloon Technique. J Interv Cardiol. 2015; 28:420-9.

15. Ermiş E, Uçar H, Demirelli S, İpek E, Gür M, Çaylı M. Assessment of side branch patency using a jailed semi-inflated balloon technique with coronary bifurcation lesions. Turk Kardiyol Dern Ars. 2018;46:340-8.

16. Saito S, Shishido K, Moriyama N, Ochiai T, Mizuno S, Yamanaka F, Sugitatsu K, Tobita K, Matsumi J, Tanaka Y, Murakami M. Modified jailed balloon technique for bifurcation lesions. Catheter Cardiovasc Interv. 2018;92:E218-26.

17. Zhang W, Ji F, Yu X, Wang X. Long-term treatment effect and adverse events of a modified jailed-balloon technique for side branch protection in patients with coronary bifurcation lesions. BMC Cardiovasc Disord. 2019;19:12.
18. Qu W, Li X, Liu B. GW29-e1527 “Balloon-stent kissing” technique avoid side-branch compromise for simple true bifurcation lesions. J Am Coll Cardiol. 2018;72(16 Supplement):C130.

19. Shpigel A, Sintek M, Singh J. The jailed stent balloon technique: a novel coronary bifurcation technique. J Am Coll Cardiol. 2018;71 (11_Supplement) A1364.

20. Numasawa Y, Sakakura K, Yamamoto K, Yamamoto S, Taniguchi Y, Fujita H, Momomura SI. A novel side branch protection technique in coronary stent implantation: Jailed Corsair technique. Cardiovasc Revasc Med. 2017;18:295-8.

21. Munakata M, Numasawa Y, Ishikawa S, Koyama T. A Novel Double Side Branch Protection Technique for a Left Main Trifurcation Lesion: Simultaneous Jailed Balloon and Jailed Corsair Technique. Case Rep Cardiol. 2018;2018:6852946.

22. Noda T. TCTAP C-042 Entrapment of Balloon in Bifurcation Lesion PCI with Jailed Balloon Technique. J Am Coll Cardiol. 2018 Apr; 71(16_Supplement)S110.

23. Numasawa Y, Hitomi Y, Imaeda S, Yokokura S, Tanaka M, Tabei R, Kodaira M. Stent deformation caused by entrapment of the side branch balloon catheter during the jailed balloon protection technique for a calcified coronary bifurcation lesion: A case report and literature review. Cardiovasc Revasc Med. 2019;20:1023-6.

24. Omori H, Kawase Y, Tanigaki T, Matsuo H. Pressure wire assessment of jailed balloon technique efficacy in a patient with complex bifurcated lesion. EuroIntervention. 2018;14:e316-7.

25. He P, Luo J, Gu M, Liu Y, Huang W, Tan N, Zhou Y, Chen J. Effect of jailed balloon technique on side branch protection in percutaneous coronary intervention for bifurcation lesions. https:// caod.oriprobe.com/articles/40422171/Effect_of_jailed_balloon technique_on_side_branch_htm

26. Jin Z, Song L, Zheng Z, Zhang S, Wang M. Balloon-stent kissing technique versus jailed wire technique for interventional treatment of coronary bifurcation lesions: Comparison of short-and long-term clinical outcomes. Medicine (Baltimore). 2019;98: e15633. 